\title{
Effect of cardiopulmonary bypass and surgical intervention on the natriuretic hormone system in children
}

\author{
John M. Costello, MD, ${ }^{\mathrm{a}, \mathrm{b}}$ Carl L. Backer, MD, ${ }^{\mathrm{c}}$ Paul A. Checchia, MD, ${ }^{\mathrm{d}}$ Constantine Mavroudis, MD, ${ }^{\mathrm{c}}$
}

Ralf G. Seipelt, MD, ${ }^{c}$ and Denise M. Goodman, MD, MSc ${ }^{b}$

From the Divisions of Cardiology, ${ }^{\text {a }}$ Critical Care Medicine, ${ }^{\mathrm{b}}$ and Cardiovascular Thoracic Surgery, ${ }^{\mathrm{c}}$ Children's Memorial Hospital, The Feinberg School of Medicine at Northwestern University, Chicago, Ill, and the Divisions of Critical Care Medicine and Cardiology, ${ }^{\mathrm{d}}$ St Louis Children's Hospital, Washington University School of Medicine, St Louis, Mo.

Funded by an internal and noncompetitive grant from The Division of CardiovascularThoracic Surgery, Children's Memorial Hospital, Chicago, Ill.

Received for publication Jan 7, 2005; revisions received Feb 28, 2005; accepted for publication March 8, 2005.

Address for reprints: John M. Costello, MD, Cardiac ICU Office, Children's Hospital Boston, 300 Longwood Ave, FA 105, Boston, MA 02115-5724 (E-mail: john. costello@cardio.chboston.org).

J Thorac Cardiovasc Surg 2005;130:822-9

$0022-5223 / \$ 30.00$

Copyright $\odot 2005$ by The American Association for Thoracic Surgery

doi:10.1016/j.jtcvs.2005.03.008
Objectives: We sought to determine the effect of cardiopulmonary bypass and surgical intervention on the natriuretic hormone system in children and to assess whether such changes are associated with morbidity.

Methods: At 6 perioperative time points in 25 patients, plasma levels of atrial natriuretic peptide, brain natriuretic peptide, and guanosine $3^{\prime}, 5^{\prime}$-monophosphate were measured, and the biologic activity of the natriuretic hormone system was quantified. Relationships were sought between changes in brain natriuretic peptide levels, biologic activity, and a number of morbidity indicators.

Results: There was a significant change in atrial natriuretic peptide levels $(P=$ $.037)$, brain natriuretic peptide levels $(P=.001)$, and biologic activity of the natriuretic hormone system $(P=.009)$ over the first 4 time points in the study. Atrial natriuretic peptide levels transiently decreased from baseline to 12 hours after surgical intervention. Compared with baseline values, brain natriuretic peptide levels were increased at 12 hours after surgical intervention and on postoperative day 1 . The increase in brain natriuretic peptide levels from baseline to 12 hours after surgical intervention was associated with cardiopulmonary bypass time $\left(r_{s}=0.4, P\right.$ $=.047)$. The biologic activity transiently decreased from baseline to intensive care unit admission but was not associated with any morbidity indicators.

Conclusions: Increased postoperative brain natriuretic peptide levels are associated with longer bypass times. The biologic activity of the natriuretic hormone system is transiently impaired. Larger studies should investigate brain natriuretic peptide as a predictor of postoperative morbidity and the potential for natriuretic hormone infusions to improve postoperative hemodynamics and urine output.

$\mathrm{T}$ he natriuretic hormone system (NHS) plays an important role in the regulation of vascular tone and fluid balance in healthy children and adults and in those with hemodynamically significant cardiac disease. ${ }^{1-4}$ However, little is known about the acute effects of cardiopulmonary bypass (CPB) and surgical intervention on the NHS or whether such an effect might have an impact on the postoperative course.

The objective of our ongoing research initiative is to determine the role of the NHS in the regulation of vascular resistance and fluid balance in infants, children, and young adults after CPB. The primary hypothesis of this study is that the calculated biologic activity of the NHS would decrease after CPB. We also hypothesized that plasma atrial natriuretic peptide (ANP) levels would decrease and brain natriuretic peptide (BNP) levels would increase in the early postoperative period, perhaps reflective of postoperative alterations in atrial stretch, volume load, and ventricular function. Finally, we sought to determine whether changes in the biologic activity of the NHS and BNP levels are associated with intraoperative and postoperative variables that predict early morbidity. 


\section{Methods}

\section{Patient Selection}

The Institutional Review Board of Children's Memorial Hospital approved the study, and written informed consent was obtained from the patients, their parents or guardians, or both. This prospective, single-center, observational study enrolled 25 patients from the following prospectively defined surgical subgroups: complete repair of intracardiac left-to-right shunt with congestive heart failure (CHF); Norwood operation; bidirectional Glenn (BDG) operation; extracardiac Fontan completion; and Fontan revision. These 5 operations are commonly performed in our institution using standardized surgical techniques. In a prior report, we described perioperative changes in the NHS in 5 infants with intracardiac left-to-right shunting and $\mathrm{CHF}^{5}$ In the current study we sought to determine whether similar changes were present after other pediatric operations that result in reduction in atrial stretch or ventricular volume load. These surgical subgroups were also selected because of the risk for postoperative fluid retention and increased vascular resistance.

\section{Surgical Repair}

The intracardiac repair, Norwood operation, BDG operation, and extracardiac, nonfenestrated Fontan operations were performed with standardized surgical techniques. Indications for revision of Fontan circulation include refractory atrial arrhythmias and anatomic obstruction of the Fontan pathway. The revision operation typically consists of conversion from an atriopulmonary Fontan connection to an extracardiac total cavopulmonary connection, wide right atrial wall excision with systematic cryoablation of the remaining atrial tissue (either a modified right-sided maze or Cox maze III), and permanent atrial pacemaker placement. Operative anesthetic management and CPB strategy followed a standard institutional protocol. Regional perfusion techniques were used to minimize the duration of circulatory arrest during the Norwood and Fontan revision procedures. All patients received aprotinin and dexamethasone intraoperatively. Modified ultrafiltration was used after CPB in 17 of 25 patients.

\section{Assay of Natriuretic Peptides}

Blood was obtained from each patient's arterial catheter at the following time points: baseline (after induction of general anesthesia and before sternotomy), 30 minutes after arrival to the intensive care unit (ICU) after surgical intervention, 12 hours after surgical intervention, and during the morning of postoperative days (PODs) 1, 2, and 3. Blood was placed in prechilled vacuum tubes containing $0.068 \mathrm{~mL}$ of $7.5 \%\left(\mathrm{~K}_{3}\right)$ ethylenediamine tetraacetic acid and immediately processed on ice. The tubes were placed in a refrigerated centrifuge, and the supernatant plasma was placed in aliquots in polystyrene tubes and frozen at $-70^{\circ} \mathrm{C}$. The plasma samples were sent to a reference laboratory (Cardiorenal Research Laboratory, Mayo Clinic, Rochester, Minn) for measurement of $\mathrm{ANP}, \mathrm{BNP}$, and their secondary messenger, guanosine $3^{\prime}, 5^{\prime}$ monophosphate (cGMP), using standardized radioimmunoassay techniques. The biologic activity of the NHS was determined at each time point by calculating the molar ratio of cGMP/(ANP + $\mathrm{BNP})$. The following molar weights were used in these calculations: ANP, $3078 \mathrm{~g} / \mathrm{mol}$; BNP, $3462 \mathrm{~g} / \mathrm{mol}$. Normal adult natriuretic hormone values as reported by the reference laboratory were used for patients older than 16 years as follows: ANP, $25 \pm 11$ $\mathrm{pg} / \mathrm{mL}$; BNP, $12 \pm 4 \mathrm{pg} / \mathrm{ml}$. Reference levels for infants and children were as follows: at birth, ANP of $129 \pm 77 \mathrm{pg} / \mathrm{mL}$ and BNP of $197 \pm 170 \mathrm{pg} / \mathrm{mL} ; 5$ days old, ANP of $120 \pm 62 \mathrm{pg} / \mathrm{mL}$ and BNP of $62 \pm 14 \mathrm{pg} / \mathrm{mL}$; less than 4 months old, ANP of 49 $\pm 15 \mathrm{pg} / \mathrm{mL}$ and $\mathrm{BNP}$ of $21 \pm 10 \mathrm{pg} / \mathrm{mL}$; less than 1 year old, ANP of $49 \pm 9 \mathrm{pg} / \mathrm{mL}$ and BNP of $7 \pm 7 \mathrm{pg} / \mathrm{mL}$; less than 5 years old, ANP of $25 \pm 12 \mathrm{pg} / \mathrm{mL}$ and BNP of $7 \pm 3 \mathrm{pg} / \mathrm{mL}$; less than 10 years old, ANP of $28 \pm 9 \mathrm{pg} / \mathrm{mL}$ and BNP of $7 \pm 3 \mathrm{pg} / \mathrm{mL}$; less than 16 years old, ANP of $31 \pm 12 \mathrm{pg} / \mathrm{mL}$ and BNP of $7 \pm 3 \mathrm{pg} / \mathrm{mL}^{6}$

At each time point, the following clinical indicators that might predict postoperative morbidity were determined. Arterial venous oxygen saturation difference was calculated by oxyhemoglobin measurements from the arterial catheter and distal superior vena cava (or from the BDG or Fontan pathways in those surgical subsets). The cardiac index was calculated with the Fick equation by using assumed oxygen consumption. Arterial lactate levels were measured with amperometry (ABL 700 Series Analyzers; Radiometer Medical A/S, Bronshoi, Denmark). An inotrope score was calculated as follows (all doses in $\mu \mathrm{g} \cdot \mathrm{kg}^{-1} \cdot \mathrm{min}^{-1}$ ):

Inotrope score $=[$ Dopamine + Dobutamine

$$
+(\text { Milrinone } \times 10)+(\text { Epinephrine } \times 100)] .
$$

CPB and aortic crossclamp times and days of postoperative ICU stay were recorded for each patient. The subjects' preoperative clinical characteristics and operative and postoperative courses were prospectively recorded.

\section{Statistics}

Statistical analysis was performed with SPSS version 10.0.5 (SPSS, Inc, Chicago, Ill). Continuous variables were reported as medians (intraquartile ranges), except where otherwise indicated. Because plasma samples were unavailable for a number of subjects on PODs 2 and 3, differences in natriuretic hormone levels and biologic activity were explored for the first 4 time points only by using the Friedman test. If an overall statistically significant difference was found, individual time points were compared with baseline by the Wilcoxon signed-rank test with a Bonferroni correction. The strength of the relationship between continuous variables was estimated by the Spearman rank correlation coefficient. Descriptive terms were used to discuss results for the surgical subgroups because small patient numbers preclude statistical analysis.

\section{Results}

Subjects

Twenty-seven consecutive patients were eligible for the study during the enrollment period, and written informed consent was obtained from 25 patients. Patient demographic data and operative procedures are listed in Table 1. Two of the 25 patients did not have a central venous catheter in the superior vena cava, and thus arterial venous oxygen saturation difference and cardiac index were not calculated (patients 15 and 24).

\section{Natriuretic Hormone Levels and Biologic Activity}

When compared with normal values for age, baseline ANP levels were increased in all of the intracardiac left-to-right 
TABLE 1. Subject diagnoses, operations, and preoperative ventricular function

\begin{tabular}{|c|c|c|c|c|c|c|c|}
\hline $\begin{array}{l}\text { Patient } \\
\text { no. }\end{array}$ & Lesion & Age (y) & Last operation & Preop Ftn* & Operation & CPB time $(\min ) \dagger$ & ACX time (min)t \\
\hline \multicolumn{6}{|c|}{ Intracardiac repair } & $94(72-118)$ & $67(46-76)$ \\
\hline 2 & CAVC, CHF & 0.45 & None & Mild $\downarrow$ & CAVC repair & & \\
\hline 3 & IAVC, CHF & 4.04 & None & Moderate $\downarrow$ & IAVC repair & & \\
\hline 4 & VSD, CHF & 0.50 & None & Normal & VSD repair & & \\
\hline 10 & VSD, CHF & 0.36 & None & Normal & VSD repair & & \\
\hline 11 & VSD, CHF & 0.54 & None & Normal & VSD repair & & \\
\hline \multicolumn{6}{|c|}{ Norwood operation } & $149(120-186)$ & $55(49-59)$ \\
\hline 6 & HLHS & 0.01 & None & Normal & Norwood & & \\
\hline 8 & Unbl CAVC, CoA & 0.01 & None & Normal & Norwood & & \\
\hline 15 & HLHS & 0.01 & None & Normal & Norwood/Sano & & \\
\hline 16 & HLHS & 0.02 & None & Normal & Norwood/Sano & & \\
\hline 23 & HLHS & 0.01 & None & Normal & Norwood/Sano & & \\
\hline \multicolumn{6}{|c|}{ Bidirectional Glenn operation } & $106(77-140)$ & None \\
\hline 18 & $\mathrm{TA}$ & 0.58 & MBTS & Normal & BDG & & \\
\hline 21 & DILV/TGA/CoA & 0.55 & Norwood & Mild $\downarrow$ & BDG & & \\
\hline 22 & DORV/TGA/PS & 3.13 & None & Normal & $\mathrm{BDG}$ & & \\
\hline 24 & TA & 0.42 & MBTS & Normal & BDG & & \\
\hline 25 & HLHS & 0.54 & Norwood/Sano & Normal & BDG & & \\
\hline \multicolumn{6}{|c|}{ Extracardiac Fontan } & $37(27-76)$ & $0(0-6)$ \\
\hline 13 & HLHS & 3.47 & BDG & Mild $\downarrow$ & Extracardiac Fontan & & \\
\hline 14 & HLHS & 2.82 & $\mathrm{BDG}$ & Mild $\downarrow$ & Extracardiac Fontan & & \\
\hline 17 & DORV/TGA/PS & 3.17 & BDG & Normal & Extracardiac Fontan & & \\
\hline 19 & DILV/TGA/CoA & 3.19 & BDG & Normal & Extracardiac Fontan & & \\
\hline 20 & PA/IVS & 3.44 & BDG & Normal & Extracardiac Fontan & & \\
\hline \multicolumn{6}{|c|}{ Fontan revision } & $201(120-243)$ & 48 (16-79) \\
\hline 1 & DILV/TGA & 19.38 & RAA-PA Fontan & Moderate $\downarrow$ & Fontan revision/CMIII & & \\
\hline 5 & $\mathrm{TA}$ & 17.41 & RAA-PA Fontan & Normal & Fontan revision & & \\
\hline 7 & $\mathrm{TA}$ & 14.53 & RAA-PA Fontan & Normal & Fontan revision & & \\
\hline 9 & DILV/TGA & 26.68 & LT Fontan & Normal & Fontan revision/CMIII & & \\
\hline 12 & $\mathrm{TA}$ & 21.58 & RAA-PA Fontan & Mild $\downarrow$ & Fontan revision & & \\
\hline
\end{tabular}

Preoperative Ftn, preoperative systemic ventricular function; $C P B$, cardiopulmonary bypass; $A C X$, aortic crossclamp; $C A V C$, complete atrioventricular canal; $C H F$, congestive heart failure; IAVC, incomplete atrioventricular canal; VSD, ventricular septal defect; HLHS, hypoplastic left heart syndrome; Unbl, unbalanced; $C O A$, coarctation of aorta; TA, tricuspid atresia; MBTS, modified Blalock-Taussig shunt; BDG, bidirectional Glenn; DILV, double-inlet left ventricle; TGA, transposition of great vessels; DORV, double-outlet right ventricle; $P S$, pulmonary stenosis; $P A / I V S$, pulmonary atresia with intact ventricular septum; RAA-PA, right atrial appendage to pulmonary artery; CMIII, Cox maze III; $L T$, lateral tunnel. *Determined by means of echocardiography or ventricular angiography. $†$ Reported as median (range).

shunt patients and 3 of 5 patients in both the Norwood and BDG subgroups (Table 2). Baseline ANP levels were normal in all of the patients undergoing the extracardiac Fontan procedure and in 4 of 5 patients undergoing Fontan revision. There was a significant change in ANP levels for the whole study group over the first 4 time points in the study $(\mathrm{n}=25$, $P=.037)$. ANP levels transiently decreased from baseline to 12 hours after the operation (Figure 1, A). When compared with baseline values, ANP levels at 12 hours after surgical repair were consistently lower in the intracardiac shunt subset. A similar trend was noted in the other subgroups: 4 of 5 ANP levels were lower at 12 hours compared with baseline values in the Norwood, BDG, and extracardiac Fontan subgroups, and 4 of 5 ANP levels were lower than baseline values on POD 1 in the Fontan revision group.
Baseline BNP levels, when compared with normal values for age, were increased in 4 of 5 patients receiving intracardiac shunts and 3 of 5 patients undergoing the Norwood procedure (the same 3 patients who had increased ANP levels, Table 2). In contrast, 13 of 15 baseline BNP levels were normal in patients in the BDG, extracardiac Fontan, and Fontan revision subgroups. For the patients in the BDG, extracardiac Fontan, and Fontan revision subgroups who had a preoperative cardiac catheterization, systemic ventricular end-diastolic pressure ranged from 5 to $14 \mathrm{~mm} \mathrm{Hg}$, which was associated with baseline BNP levels $(\mathrm{n}=14$, Spearman's rho $=0.69, P=.006$ ). There was a significant change in BNP levels over the first 4 time points in the study (n $=25, P=.001)$. Compared with baseline values, BNP levels were increased at 12 hours after surgical intervention 
TABLE 2. Natriuretic hormone levels for surgical subgroups*

\begin{tabular}{|c|c|c|c|c|c|c|c|}
\hline Operation & & Baseline & ICU admit & $12 \mathrm{~h}$ & POD 1 & POD 2 & POD 3 \\
\hline \multirow[t]{2}{*}{ Intracardiac repair } & ANP & 164 (63-339) & $62(51-108)$ & $57(16-79)$ & $56(30-90)$ & $131(68-263)$ & $133(112-188)$ \\
\hline & BNP & $91(4-301)$ & $69(9-230)$ & $124(59-846)$ & $63(15-880)$ & $118(41-722)$ & $94(60-138)$ \\
\hline \multirow[t]{2}{*}{ Norwood } & ANP & $337(65-521)$ & $243(51-340)$ & $167(55-260)$ & $129(66-509)$ & 137 (123-259) & $144(80-171)$ \\
\hline & BNP & $208(28-413)$ & $360(169-586)$ & $462(261-543)$ & $403(170-603)$ & $275(65-521)$ & $95(33-131)$ \\
\hline \multirow{2}{*}{$\mathrm{BDG}$} & ANP & 71 (34-82) & $94(14-118)$ & 37 (12-63) & $28(15-77)$ & $58(27-85)$ & 65 (42-105) \\
\hline & BNP & $14(4-21)$ & $29(18-67)$ & $48(31-212)$ & $75(34-136)$ & $54(27-66)$ & $46(10-65)$ \\
\hline \multirow[t]{2}{*}{ Extracardiac Fontan } & ANP & $24(9-54)$ & $58(12-135)$ & $9(6-28)$ & $37(16-85)$ & $62(34-97)$ & $69(18-102)$ \\
\hline & BNP & $8(4-37)$ & $23(4-37)$ & $32(5-51)$ & $17(6-75)$ & $33(22-90)$ & $22(8-56)$ \\
\hline \multirow[t]{2}{*}{ Fontan revision } & ANP & $47(22-123)$ & 64 (14-77) & $51(26-88)$ & $16(12-117)$ & $65(20-130)$ & $50(2-220)$ \\
\hline & BNP & $22(19-54)$ & $32(19-84)$ & 53 (34-203) & $33(20-185)$ & $35(26-106)$ & $56(24-253)$ \\
\hline
\end{tabular}

$I C U$, Intensive care unit; $P O D$, postoperative day; $A N P$, atrial natriuretic peptide; $B N P$, brain natriuretic peptide; $B D G$, bidirectional Glenn. *Atrial natriuretic peptide and brain natriuretic peptide levels are presented in picograms per milliliter. Data are reported as median (range).

and on POD 1 (Figure 1, $B$ ). Figure 2 illustrates the changes in BNP levels over time for the Norwood subgroup. A similar trend of increasing BNP levels was seen in the other surgical subgroups because 3 of 5 BNP levels were higher at 12 hours after surgical intervention compared with baseline values in the intracardiac repair and extracardiac Fontan groups, 4 of 5 BNP levels were higher at 12 hours compared with baseline values in the Fontan revision group, and 5 of 5 BNP levels were higher at 12 hours compared with baseline values in the BDG group (Table 2).

There was no significant change in plasma cGMP concentrations over the first 4 time points in the study $(\mathrm{n}=22$, $P=.44$, Figure $1, C)$. There was a significant change in the biologic activity of the NHS over the first 4 time points in the study (n $=21, P=.009$ ). Biologic activity transiently decreased from baseline to ICU admission (Figure 3). Similar trends were found in each of the surgical subgroups, with the exception of the patients with CHF undergoing intracardiac repair (data not shown).

A positive association was found between the change in BNP levels for the whole study group from baseline to 12 hours after surgical intervention and CPB time $(n=25$, Spearman's rho $=0.4, P=.047)$. Similar trends were noted between the change in BNP levels from baseline to 12 hours after surgical intervention and aortic crossclamp time $(P=$ $.066)$ and arterial lactate levels 12 hours after surgical intervention $(P=.058)$. These findings were clearly influenced by data from the 5 patients undergoing the Norwood operation, and removal of these patients from the analysis weakens the relationships. No significant association was found between the change in BNP levels from baseline to 12 hours after surgical intervention and cardiac index or inotropic score at that time point or days of postoperative ICU stay. No significant association was found between the change in NHS biologic activity from baseline to ICU admission and any of the clinical indicators.

\section{Discussion}

Natriuretic hormones bind to dedicated receptors in the vascular endothelium, myocardium, and kidneys, which activate guanylyl cyclase, leading to production of cGMP. cGMP-dependent protein kinases act on several intracellular substrates to reduce cytosolic calcium and cause smooth and cardiac myocyte relaxation. ${ }^{7}$ In the kidney natriuretic hormones promote diuresis directly by causing afferent arteriolar vasodilation and efferent arteriolar vasoconstriction, which increases the glomerular filtration rate. ${ }^{8}$ Natriuretic hormones indirectly augment urine output by inhibiting the effects of the sympathetic nervous system and angiotensin II on proximal tubular sodium absorption, blunting aldosterone production, and inhibiting vasopressin's effect at the medullary collecting duct. ${ }^{9}$ The NHS has diagnostic, prognostic, and therapeutic utility in adults with CHF. ${ }^{1,10,11}$ Predictable increases in natriuretic hormone levels occur in children with congenital heart defects. ${ }^{2-4}$ Because several of the pathophysiologic features encountered in CHF mimic those seen after CPB, including neurohumoral activation, myocardial dysfunction, increased vascular resistance, and fluid retention, it is intuitively attractive to investigate the NHS in the immediate postoperative period in infants and children.

The results of this study suggest that important changes in the NHS occur in infants and children who are exposed to $\mathrm{CPB}$ during the course of cardiac surgical repair or palliation. The observation that ANP levels transiently decreased postoperatively might be mechanistically explained by reduction of atrial stretch and volume overload, as has been proposed in adults after mitral valvuloplasty. ${ }^{12}$ In the intracardiac shunt group the large left-to-right shunt was eliminated after surgical intervention, and the observed decrease in ANP levels is similar to that seen in prior reports by our group and other investigators. ${ }^{5,13}$ Infants with hypoplastic left heart syndrome typically experience significant pulmonary overcirculation because their pulmonary vascular re- 


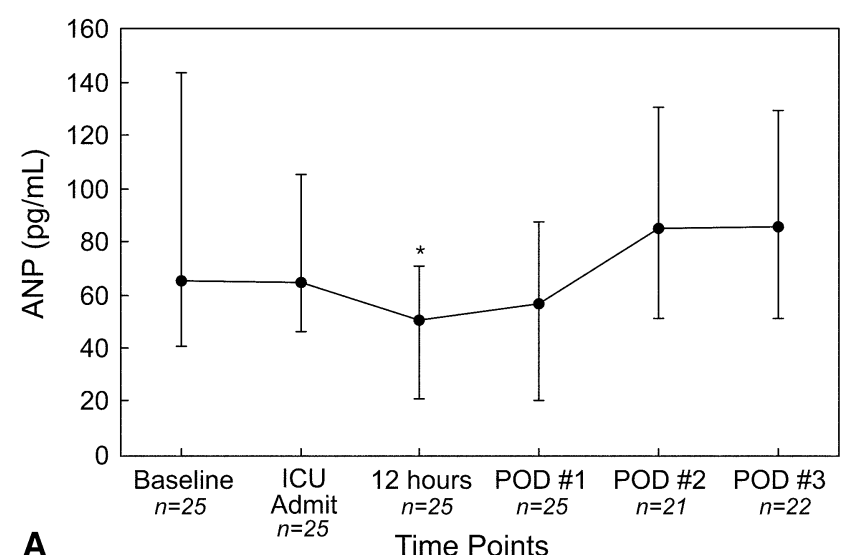

A
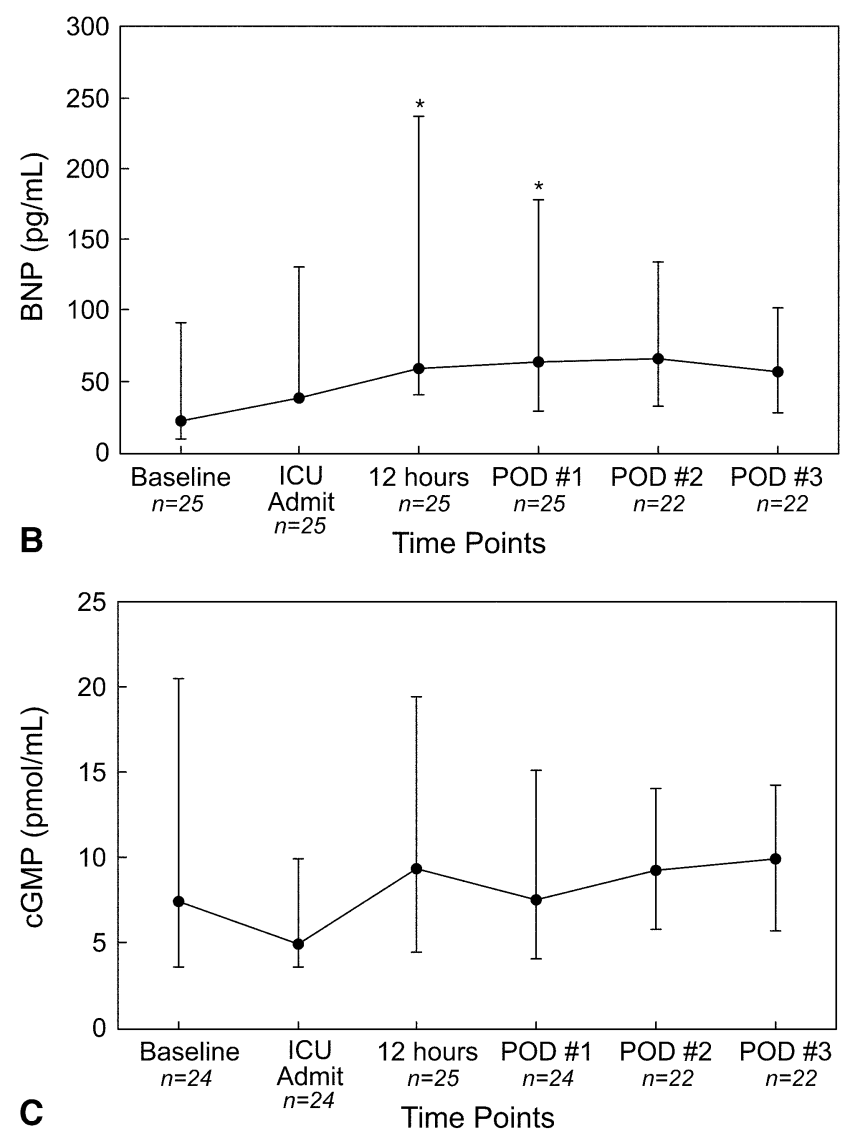

Figure 1. A, ANP levels over time for all study patients. B, BNP levels over time for all study patients. C, cGMP levels over time for all study patients (*significant difference vs baseline).

sistance decreases while awaiting surgical intervention, and after the Norwood procedure, a more balanced circulation is present because of fixed obstruction provided by the pulmonary shunt. The BDG operation provides a substantial reduction of volume load to the heart. In contrast to the atriopulmonary Fontan procedure, which has been associ-

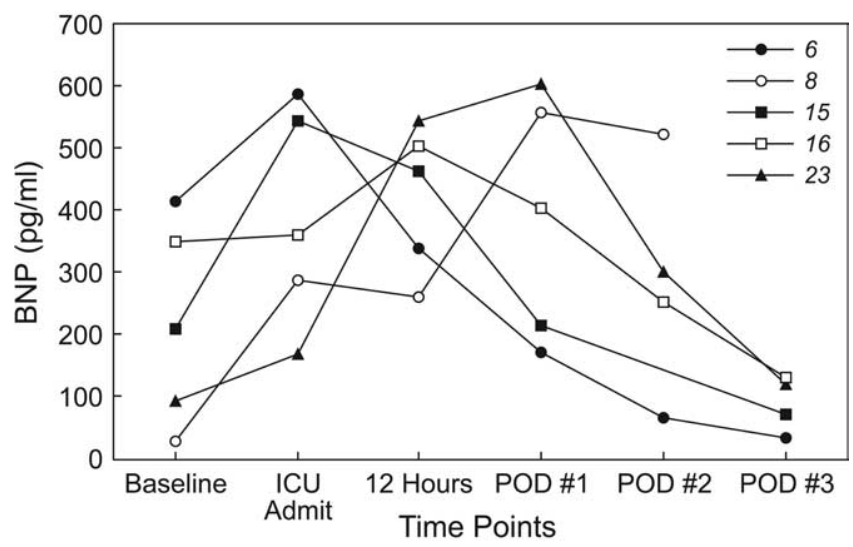

Figure 2. Change in BNP levels over time for the patients undergoing a Norwood operation. Three of the 5 patients had increased preoperative BNP levels for age, likely reflective of a significant volume overload of the single ventricle. Patients $8,15,16$, and 23 , all of whom required an epinephrine infusion postoperatively, had higher BNP levels for an extended period of time compared with patient 6, who did not require epinephrine. Patient 8 had a marked and sustained increase in BNP levels and died on POD 2 of neoaortic insufficiency, pulmonary hypertension, and low cardiac output. Note that patient 15 did not have a BNP level measured on POD 2.

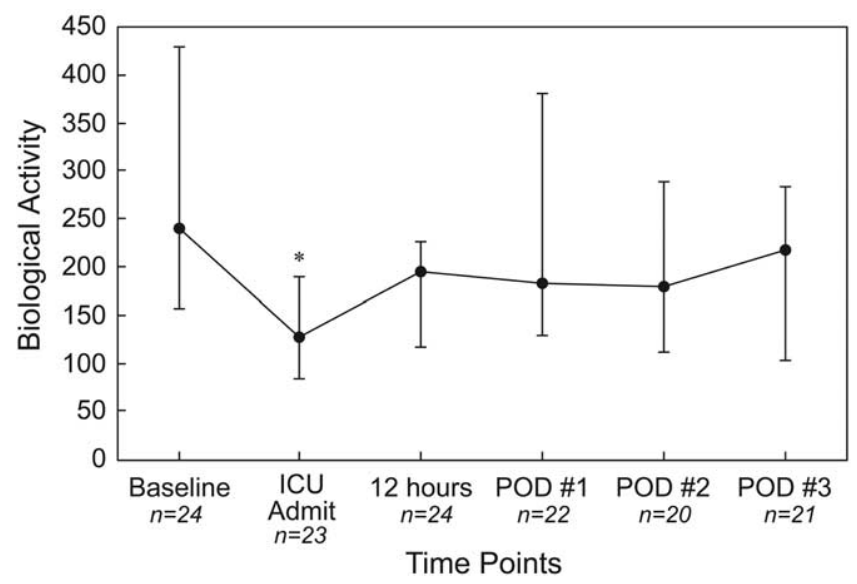

Figure 3. Biologic activity over time for all study patients (*significant difference vs baseline).

ated with an increase in ANP levels, this study and others have documented either unchanged or decreasing ANP levels after the extracardiac Fontan procedure. ${ }^{14,15}$ The subsequent increase in ANP levels for the whole study group on PODs 1 through 3 is difficult to explain, but potential causes include ANP production by the ventricular myocardium or impaired clearance of ANP by natriuretic peptide clearance receptors or neutral endopeptidases. ${ }^{16-18}$ 
We found a significant postoperative increase in BNP levels for the whole study group that was associated with CPB times, and similar trends exist for aortic crossclamp times and lactate levels at 12 hours after surgical intervention. The increase in BNP levels might be attributable in part to the effects of CPB and surgical manipulation on myocardial function and wall stress. Although not formally evaluated in this study, increasing BNP levels have a negative association with indices of myocardial function after valvular or coronary bypass surgery in adults. ${ }^{19}$ An increase in early postoperative BNP levels has been previously reported after repair of tetralogy of Fallot and intracardiac left-to-right shunts and after extracardiac Fontan completion. ${ }^{5,15}$ The extent of the increase in BNP levels has been associated with longer aortic crossclamp times, with potential for myocardial ischemia-reperfusion injury in adults, and a trend toward such an effect was seen in this study. ${ }^{19,20}$

Although no association was found between inotropic scores and the change in BNP levels for the whole study population, increasing BNP levels might be predictive of the need for significant inotropic support in selected subgroups, as was seen in our patients undergoing the Norwood operation (Figure 2). In the Fontan revision subgroup the single patient who required an epinephrine infusion postoperatively had a marked increase in BNP levels and a prolonged ICU stay when compared with the other members of this subgroup. The ability of BNP levels to predict postoperative morbidity and mortality requires investigation in a larger number of similar patients.

In this study we used the molar ratio of cGMP/(ANP + BNP) to quantify the biologic activity of the NHS. Other investigators have reported using the molar ratio of cGMP/ ANP for this purpose. ${ }^{13,21}$ The use of a single peptide in such calculations does not appear to be fundamentally sound because cGMP is the secondary mediator for multiple peptides in the natriuretic hormone family. We previously suggested that the ratio of cGMP/(ANP + BNP + Dendroaspis natriuretic peptide) might provide the most comprehensive assessment of the biologic activity of the NHS. ${ }^{5}$ In the current study, we did not measure Dendroaspis natriuretic peptide because levels of this peptide did not appreciably change after CPB in our prior study. C-type natriuretic peptide and urodilitin are additional members of the natriuretic hormone family that act in paracrine fashion within the vascular endothelium and kidney, respectively. ${ }^{22,23}$ Because C-type natriuretic peptide and urodilitin concentrations are not increased in the plasma of adults with $\mathrm{CHF}$, these peptides were not measured during this study.

Because the biologic effects of cGMP are considered to be a consequence of increased intracellular levels of this messenger, the use of plasma levels of cGMP is an indirect assessment of the biologic effects of the NHS. The ability of natriuretic peptides to increase intracellular and extracellu- lar cGMP levels in vascular smooth muscle and endothelial cell culture models is well established, and the measurement of plasma or urine cGMP levels as a marker of endogenous and exogenous natriuretic hormone activity has been reported in a number of adult and pediatric studies. ${ }^{24}$ cGMP is also the secondary mediator for nitric oxide, and disturbances in this system after CPB could influence cGMP levels. However, plasma cGMP levels do not correlate with nitrate and nitrite levels, markers of nitric oxide production, in children undergoing $\mathrm{CPB} .{ }^{13}$

The mechanism by which $\mathrm{CPB}$ impairs the biologic activity of the NHS is not known, and this study was not designed to explore this issue. The biologic activity of the NHS in adults with severe CHF might be decreased because of natriuretic peptide receptor downregulation or disturbances in postreceptor signal transduction. ${ }^{25}$ Increased phosphodiesterase activity might decrease cGMP levels, as has been observed in experimental $\mathrm{CHF}^{26}$ In cell culture models hypothermia impairs ANP receptor-ligand dissociation, which might decrease cGMP production, and cellular egress of cGMP. ${ }^{24,27}$

Decreased biologic activity of the NHS might play a role in the development of fluid retention and increased vascular resistance, which typically occur after pediatric $\mathrm{CPB}$. In this study we were unable to detect any relationship between the biologic activity of the NHS and several previously reported measures of postoperative morbidity and mortality. However, preliminary reports suggest that the infusion of natriuretic peptides has favorable hemodynamic and renal effects after CPB in adults. ${ }^{28}$ In the only published pediatric study of perioperative natriuretic hormone infusions, 8 children after the Fontan operation received a 1-hour infusion of ANP, resulting in increased urine output, decreased pulmonary vascular resistance and central venous filling pressure, and favorable trends in cardiac index and systemic vascular resistance. $^{29}$

\section{Limitations}

This study is limited by the small number of patients enrolled and the high intraindividual and interindividual variability in the NHS. Objective assessment of ventricular function and vascular resistance would have enabled us to determine whether relationships existed between these variables and BNP levels and NHS biologic activity. The use of assumed oxygen consumption in the Fick equation to calculate cardiac output is problematic because oxygen consumption might be quite variable after $\mathrm{CPB} .{ }^{30}$ Although we did not measure oxygen consumption or use thermodilution catheters to calculate cardiac output, all patients were deeply sedated and mechanically ventilated until at least the first postoperative day, likely making the cardiac output measurements more reliable for a least the first 4 time points in the study. The use of modified ultrafiltration in 17 of 25 
patients in this study is a confounding variable because natriuretic peptides and cGMP might be eliminated across the filtration membrane. During a previous investigation, ${ }^{5}$ we measured levels of natriuretic peptides and cGMP in the ultrafiltrate collected from 5 infants who had undergone conventional ultrafiltration during rewarming on CPB followed by 10 minutes of modified ultrafiltration (unpublished data). Median ultrafiltrate ANP levels were 2118 $\mathrm{pg} / \mathrm{mL}$ (range, 708-2603 pg/mL), approximately 6-fold higher than simultaneous plasma levels. Median BNP levels were $3.4 \mathrm{pg} / \mathrm{mL}$ (range, $1-4.3 \mathrm{pg} / \mathrm{mL}$ ), approximately $25 \%$ of plasma levels obtained at the same time period. Median cGMP levels were $19.4 \mathrm{pmol} / \mathrm{mL}$ (range, $6.4-21.2 \mathrm{pmol} /$ $\mathrm{mL}$ ), approximately twice as high as simultaneous plasma levels. These findings might be explained by the fact that plasma ANP and cGMP concentrations were relatively preserved compared with baseline values during CPB and thus available at higher concentrations for filtration, whereas plasma BNP levels precipitously decreased during CPB.

\section{Conclusions}

Systematic changes in natriuretic hormone levels occur after congenital heart surgery involving CPB. Increasing BNP levels are associated with longer CPB times. The biologic activity of the NHS is transiently impaired in the early postoperative period. Further investigation is warranted to elucidate the clinical significance of these observations in larger numbers of infants, children, and young adults undergoing similar procedures and to determine whether the use of natriuretic hormone infusions favorably affects the postoperative course after CPB.

We thank Kimberlee Gauvreau, ScD, from the Children's Hospital Boston and Harvard Medical School for her valuable statistical input.

\section{References}

1. Chen HH, Burnett JC Jr. The natriuretic peptides in heart failure: diagnostic and therapeutic potentials. Proc Assoc Am Physicians. 1999;111:406-16.

2. Suda K, Matsumura M, Matsumoto M. Clinical implication of plasma natriuretic peptides in children with ventricular septal defect. Pediatr Int. 2003;45:249-54.

3. Wahlander H, Westerlind A, Lindstedt G, Lundberg PA, Holmgren D. Increased levels of brain and atrial natriuretic peptides after the first palliative operation, but not after a bidirectional Glenn anastomosis, in children with functionally univentricular hearts. Cardiol Young. 2003; 13:268-74.

4. Ohuchi H, Takasugi H, Ohashi H, Okada Y, Yamada O, Ono Y, et al. Stratification of pediatric heart failure on the basis of neurohormonal and cardiac autonomic nervous activities in patients with congenital heart disease. Circulation. 2003;108:2368-76.

5. Costello JM, Backer CL, Checchia PA, Mavroudis C, Goodman DM. Alterations in the natriuretic hormone system related to cardiopulmonary bypass and modified ultrafiltration in patients with congenital heart disease. Pediatr Cardiol. 2004;25:347-53.

6. Yoshibayashi M, Kamiya T, Saito Y, Nakao K, Nishioka K, Temma S, et al. Plasma brain natriuretic peptide concentrations in healthy children from birth to adolescence: marked and rapid increase after birth. Eur J Endocrinol. 1995;133:207-9.
7. Munzel T, Feil R, Mulsch A, Lohmann SM, Hofmann F, Walter U. Physiology and pathophysiology of vascular signaling controlled by guanosine $3^{\prime}, 5^{\prime}$-cyclic monophosphate-dependent protein kinase. Circulation. 2003;108:2172-83.

8. Dunn BR, Ichikawa I, Pfeffer JM, Troy JL, Brenner BM. Renal and systemic hemodynamic effects of synthetic atrial natriuretic peptide in the anesthetized rat. Circ Res. 1986;59:237-46.

9. Costello-Boerrigter LC, Boerrigter G, Burnett JC Jr. Revisiting salt and water retention: new diuretics, aquaretics, and natriuretics. Med Clin North Am. 2003;87:475-91.

10. Maisel AS, Krishnaswamy P, Nowak RM, McCord J, Hollander JE, Duc P, et al. Rapid measurement of B-type natriuretic peptide in the emergency diagnosis of heart failure. $N$ Engl J Med. 2002;347:161-7.

11. The VMAC Investigators. Intravenous nesiritide vs nitroglycerin for treatment of decompensated congestive heart failure: a randomized controlled trial. JAMA. 2002;287:1531-40.

12. Kharasch ED, Yeo KT, Kenny MA, Amory DW. Influence of hypothermic cardiopulmonary bypass on atrial natriuretic factor levels. Can J Anaesth. 1989;36:545-53.

13. Seghaye MC, Duchateau J, Bruniaux J, Demontoux S, Detruit H, Bosson C, et al. Endogenous nitric oxide production and atrial natriuretic peptide biological activity in infants undergoing cardiac operations. Crit Care Med. 1997;25:1063-70.

14. Stewart JM, Seligman KP, Zeballos G, Romano A, Clarke BJ, Woolf $\mathrm{PK}$, et al. Elevated atrial natriuretic peptide after the Fontan procedure. Circulation. 1987;76(Suppl III):III77-82.

15. Yoshimura N, Yamaguchi M, Oshima Y, Oka S, Ootaki Y, Hasegawa $\mathrm{T}$, et al. Suppression of the secretion of atrial and brain natriuretic peptide after total cavopulmonary connection. J Thorac Cardiovasc Surg. 2000;120:764-9.

16. Lee RT, Bloch KD, Pfeffer JM, Pfeffer MA, Neer EJ, Seidman CE. Atrial natriuretic factor gene expression in ventricles of rats with spontaneous biventricular hypertrophy. J Clin Invest. 1988;81: 431-4.

17. Fuller F, Porter JG, Arfsten AE, Miller J, Schilling JW, Scarborough $\mathrm{RM}$, et al. Atrial natriuretic peptide clearance receptor. Complete sequence and functional expression of cDNA clones. J Biol Chem. 1988;263:9395-401.

18. Kenny AJ, Stephenson SL. Role of endopeptidase-24.11 in the inactivation of atrial natriuretic peptide. FEBS Lett. 1988;232:1-8.

19. Morimoto K, Mori T, Ishiguro S, Matsuda N, Hara Y, Kuroda H. Perioperative changes in plasma brain natriuretic peptide concentrations in patients undergoing cardiac surgery. Surg Today. 1998;28: 23-9.

20. Mair P, Mair J, Bleier J, Hormann C, Balogh D, Puschendorf B. Augmented release of brain natriuretic peptide during reperfusion of the human heart after cardioplegic cardiac arrest. Clin Chim Acta. 1997;261:57-68.

21. Hayashida N, Chihara S, Kashikie H, Tayama E, Yokose S, Akasu K, et al. Biological activity of endogenous atrial natriuretic peptide during cardiopulmonary bypass. Artif Organs. 2000;24:833-8.

22. Chen HH, Burnett JC. C-type natriuretic peptide: the endothelial component of the natriuretic peptide system. J Cardiovasc Pharmacol. 1998;32(suppl):S22-8.

23. Herten M, Lenz W, Gerzer R, Drummer C. The renal natriuretic peptide urodilatin is present in human kidney. Nephrol Dial Transplant. 1998;13:2529-35.

24. Hamet P, Pang SC, Tremblay J. Atrial natriuretic factor-induced egression of cyclic guanosine $3^{\prime}, 5^{\prime}$-monophosphate in cultured vascular smooth muscle and endothelial cells. J Biol Chem. 1989;264: 12364-9.

25. Tsutamoto T, Kanamori T, Wada A, Kinoshita M. Uncoupling of atrial natriuretic peptide extraction and cyclic guanosine monophosphate production in the pulmonary circulation in patients with severe heart failure. J Am Coll Cardiol. 1992;20:541-6.

26. Supaporn T, Sandberg SM, Borgeson DD, Heublein DM, Luchner $\mathrm{A}$, Wei CM, et al. Blunted cGMP response to agonists and enhanced glomerular cyclic $3^{\prime}, 5^{\prime}$-nucleotide phosphodiesterase activities in experimental congestive heart failure. Kidney Int. 1996;50: 1718-25. 
27. Koh GY, Nussenzveig DR, Okolicany J, Price DA, Maack T. Dynamics of atrial natriuretic factor-guanylate cyclase receptors and receptorligand complexes in cultured glomerular mesangial and renomedullary interstitial cells. J Biol Chem. 1992;267:11987-94.

28. Hayashi Y, Ohtani M, Hiraishi T, Kobayashi Y, Nakamura T. Synthetic human alpha-atrial natriuretic peptide infusion in management after open heart operations. ASAIO J. 2003;49:320-4.
29. Hiramatsu T, Imai Y, Takanashi Y, Seo K, Terada M, Nakazawa M. Hemodynamic effects of human atrial natriuretic peptide after modified Fontan procedure. Ann Thorac Surg. 1998;65:761-4.

30. Li J, Bush A, Schulze-Neick I, Penny DJ, Redington AN, Shekerdemian LS. Measured versus estimated oxygen consumption in ventilated patients with congenital heart disease: the validity of predictive equations. Crit Care Med. 2003;31:1235-40.

Access to The Journal of Thoracic and Cardiovascular Surgery Online is reserved for print subscribers!

Full-text access to The Journal of Thoracic and Cardiovascular Surgery Online is available for all print subscribers. To activate your individual online subscription, please visit The Journal of Thoracic and Cardiovascular Surgery Online, point your browser to http://www.mosby.com/jtcvs, follow the prompts to activate your online access, and follow the instructions. To activate your account, you will need your subscriber account number, which you can find on your mailing label (note: the number of digits in your subscriber account number varies from 6 to 10). See the example below in which the subscriber account number has been circled:

\section{Sample mailing label}

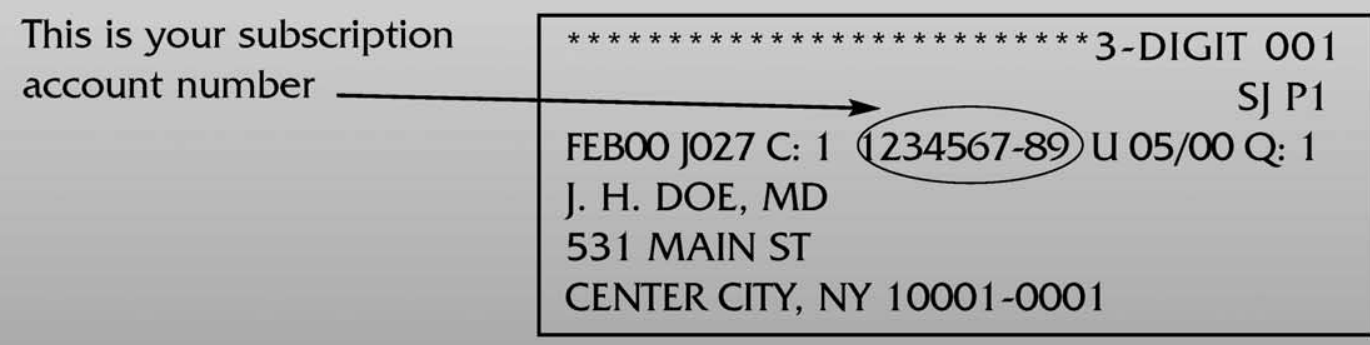

Personal subscriptions to The Journal of Thoracic and Cardiovascular Surgery Online are for individual use only and may not be transferred. Use of The Journal of Thoracic and Cardiovascular Surgery Online is subject to agreement to the terms and conditions as indicated online. 